\title{
The Study of Folding Defects during the Radial-Forward Extrusion in the Enclosed Dies
}

\author{
Dr. Payman Abhari
}

Ph.D., Associate Professor of Metal Forming Department, Donbass State Engineering Academy, Ukraine

\begin{abstract}
In this paper, the radial-forward extrusion process in the enclosed dies to create precision parts is considered. The numerical simulation techniques by using the rigid-plastic finite element method (FEM) as software QForm $2 D$ have been applied to investigate in this paper. Based on the finite element simulations, forming characteristics such as patterns (gridlines distortion), distributions of effective strain and stress at several stages of process with different forming parameters, the relative pressure variations on the punch with different relationships parameters and also to predict and avoid folding defect in radial-forward extrusion process have been investigated by using this numerical simulation method.
\end{abstract}

Keywords: Cold forging, Enclosed die, Finite element simulation, Radial-forward extrusion

\section{Introduction}

The growth of the metal forming industry has increased. This increase is due to development of new and more advanced equipments, presses and materials. Product quality, cost and time to market are three overriding issues in metal forming industry. Defects occurring as folding defect during metal forming processes sometimes are caused. It is very important and necessary to control material flow during the process to avoid the formation of folding defect. On the other hand, the use of numerical analysis as finite element, it is necessary to investigate in different fields of metal forming processes. Due to this, the use of finite element method based on computer aided design and engineering techniques for process simulation has been increasing each year. Metal forming can be classified into cold, warm, and hot forging. In recent years, there has been a greater need for enclosed cold forging technology to provide precision parts with various shapes. Extrusion process with room temperature is type of cold forging process. By this process can be produced axisymmetric and non-axisymmetric parts. There are principal types of extrusion process such as forward, backward, radial, lateral and combined. The radial-forward extrusion process is a combined process in which a billet is extruded simultaneously in the radial and forward directions relative to the punch movement [1-10].

\section{Method of Analysis}

In the radial-forward extrusion process with enclosed dies, the numerical simulation techniques by using the rigid-plastic finite element method (FEM) as software QForm 2D have been applied to investigate the different forming characteristics and parameters at several stages of process.

\section{Purpose of Investigation}

In this paper, to create precision parts by radial-forward extrusion have been used enclosed dies. Based on the finite element simulations, forming characteristics such as patterns (gridlines distortion), distributions of effective strain and stress at several stages of process with different forming parameters and also to predict and avoid folding defect in radial-forward extrusion process have been investigated by using this theoretical simulation method.

\section{Radial-Forward Extrusion Process}

The die scheme, die geometries, billet dimensions and the formed part for radial-forward extrusion process with enclosed dies are shown in figure 1. A cylindrical billet is considered. The die geometry parameters, billet dimensions and power mode parameters are as follows: $R_{1}$ - the radius of billet $\left(R_{1}=25 \mathrm{~mm}\right), R_{2}-$ the inner radius of formed part $\left(R_{2}=35 \mathrm{~mm}\right), R_{3}$ - the outer radius of formed part $\left(\mathrm{R}_{3}=50 \mathrm{~mm}\right), \mathrm{h}$ - the flange height, $\mathrm{t}-$ The difference between outer radius and inner radius of formed part $\left(R_{3}-R_{2}\right)$, $\mathrm{h} / \mathrm{t}=1.0,1.4,1.8 ; \mathrm{L}-$ the billet height $(\mathrm{L}=150 \mathrm{~mm}), \mathrm{r}_{1}-$ mandrel radius $\left(r_{1}=2,4,6 \mathrm{~mm}\right), r_{2}-$ deflection radius $\left(r_{2}=2 \mathrm{~mm}\right), r_{3}-$ die radius $\left(r_{3}=2 \mathrm{~mm}\right), V-$ punch velocity $(\mathrm{V}=1 \mathrm{~mm} / \mathrm{s}), \mathrm{P}-$ punch load, The friction factors between the billet and tools are constant (Zibel's law, $\mu=0.08$ ).

\section{Material Property}

In this study, the material used for the simulation is AA 6060 aluminum alloy. The relationship between flow stress and effective strain for AA 6060 aluminum alloy can be approximated by:

$$
\bar{\sigma}=191.55 \bar{\varepsilon}^{0.202}(M P a)
$$




\section{International Journal of Science and Research (IJSR) \\ ISSN (Online): 2319-7064}

Index Copernicus Value (2015): 78.96 | Impact Factor (2015): 6.391

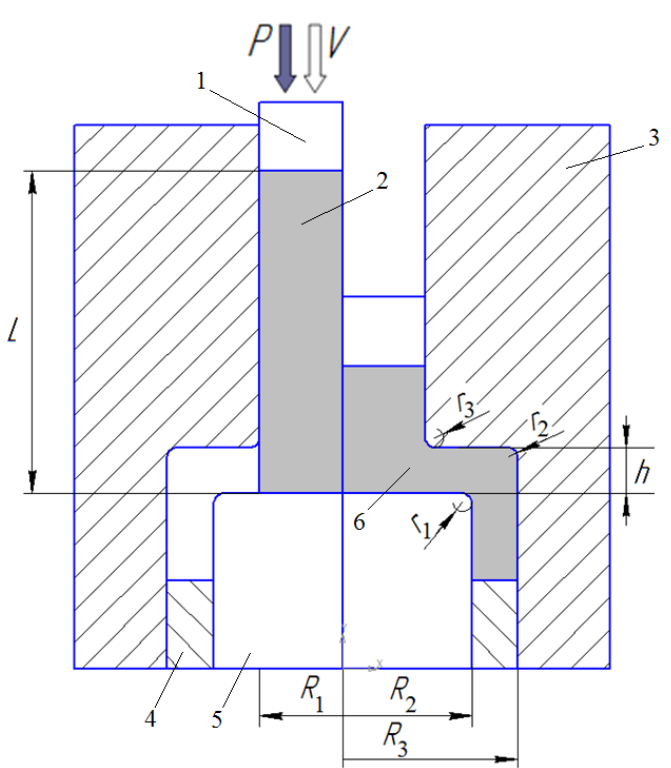

(a)

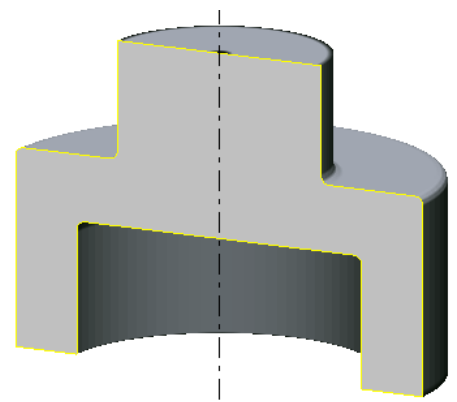

(b)

Figure 1: Scheme of radial-forward extrusion process with enclosed dies (a) and formed part (b), 1 - punch, 2 - billet, 3 - upper die, 4 - anvil (counterpunch), 5 - mandrel, 6 formed part

\section{Analysis of Radial-Forward Extrusion Process}

During the radial-forward extrusion process with an axisymmetric billet, a movable punch that is a rigid body applies force on billet material and the material flows to form the formed part in die cavity. To simulate a material flow, QForm 2D, a commercial software for plastic deformation simulation, is considered. The billet is modeled as a rigid-plastic body, the punch and other tools are modeled as rigid bodies. In cold forging as radial-forward extrusion billet, punch and tooling temperature are room temperature. Deformation patterns (gridlines distortion), distributions of effective strain and stress for this extrusion process with different values of punch stroke $(S)$ per billet radius $\left(R_{1}\right)$ are shown in figure 2 . It is observed in the figures that the maximum amounts will be in a relationship $S / R_{1}=4.2$.

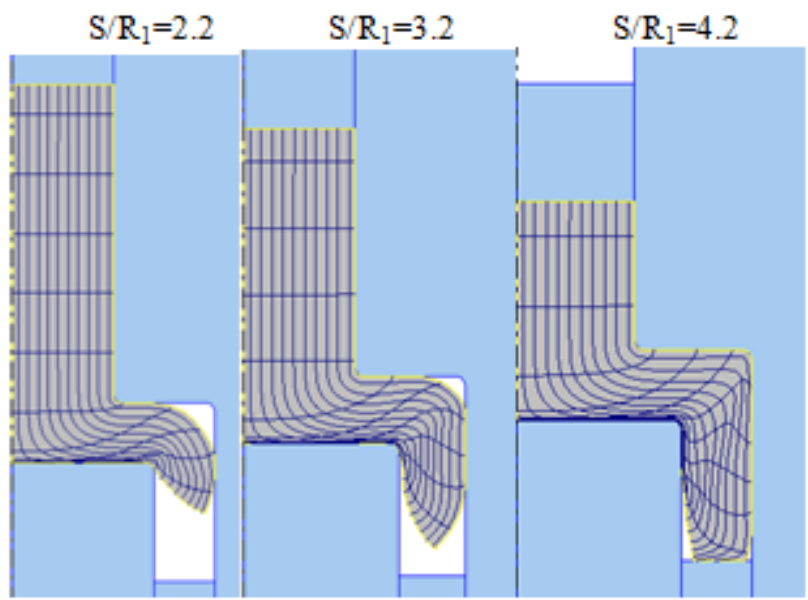

(a)

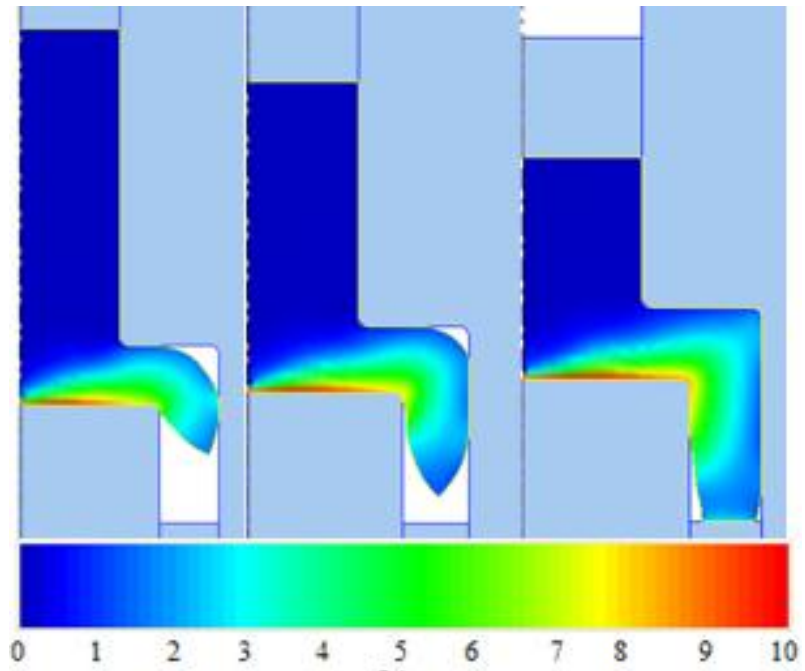

(b)

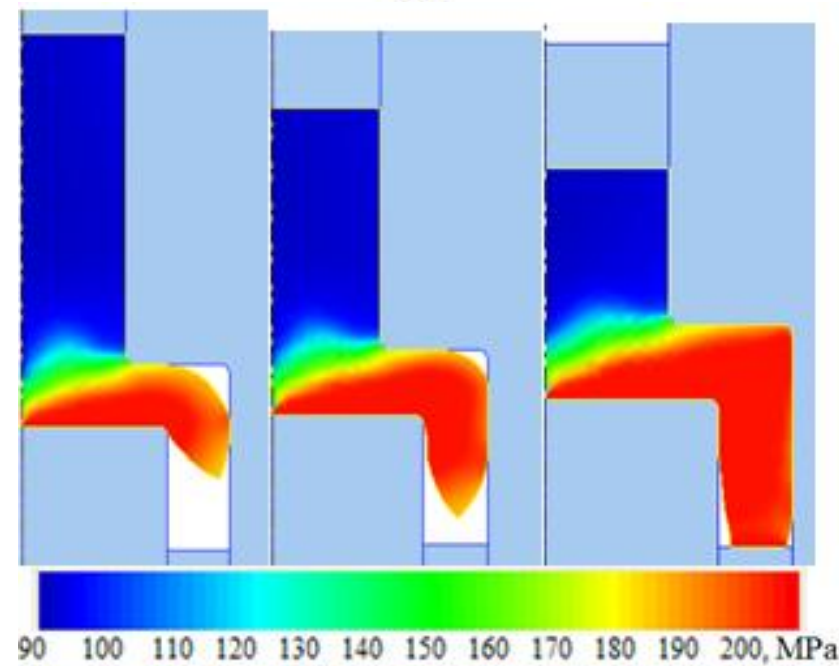

(c)

Figure 2: Gridlines distortion (a); distributions of effective strain (b); distributions of effective stress (c) with different stages $S / R_{0}$ in radial-forward extrusion process with enclosed dies

The relative pressure variations on the punch with punch travel as determined by finite element simulation. The relative punch pressure vs. the relative punch strokes with different relationships $\left(h / \mathrm{R}_{1}\right)$ in radial-forward extrusion process are shown in figure 3 .

\section{Volume 6 Issue 7, July 2017 www.ijsr.net}




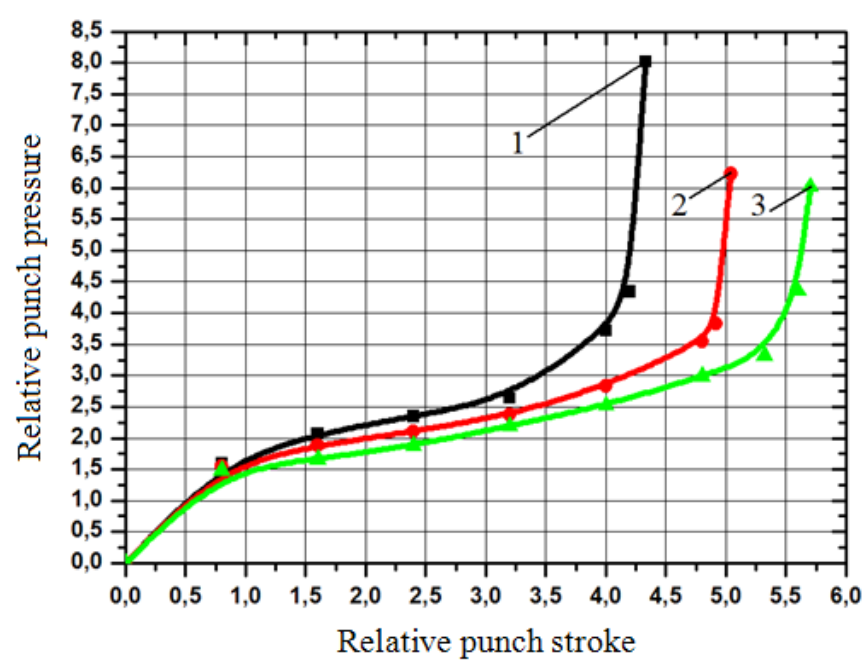

Figure 3: The relative punch pressure vs. the relative punch stroke with different relationships $\left(\mathrm{h} / \mathrm{R}_{1}\right)$ in radial-forward extrusion process. $1-\mathrm{h} / \mathrm{R}_{1}=1.0,2-\mathrm{h} / \mathrm{R}_{1}=1.4, \mathrm{~h} / \mathrm{R}_{1}=1.8$

It can be observed that on the curves in figure 3, three principal stages are as follows: coining stage, steady state stage and unsteady state stage are occurred and relative punch pressures increase along the any stage of the deformation. The results of relative punch pressures comparison between three curves in figure 3 show that relative pressure on the punch with relationship $h / R_{1}=1.0$ greater than relationships $h / R_{1}=1.4$ and $h / R_{1}=1.8$. This is because the material flows in die cavity filling occur hardly with $h / R_{1}=1.0$. It is very important and necessary in this process study to predict and avoid defect as a folding defect. Figure 4 shows a folding defect on the material flow with different mandrel radius $\left(r_{1}\right)$. A finite element simulation as shown in figure 5 is developed to study the defect formation mechanism. Figure 5 shows that there are two major stages to avoid a folding defect. In the first stage, when the punch presses the billet, the material under the punch moves down and contacts with the anvil (4) and fills die cavity (figure 5a). In the second stage, the anvil moves down and after that the punch presses the deformed part, material moves down and fills die cavity (figure 5-b). Based on the used methods for $\mathrm{r}_{1}=4 \mathrm{~mm}$ or $\mathrm{r}_{1}=6 \mathrm{~mm}$ can be produced precision parts without folding defect in radial-forward extrusion process.

\section{Conclusion}

The material behavior, stress-strain state, the relative pressure variations on the punch, and also to predict and avoid folding defect by finite element method (QForm 2D) are investigated. The simulation results are shown that relative pressure on the punch with relationship $h / R_{1}=1.0$ greater than relationships $h / R_{1}=1.4$ and $h / R_{1}=1.8$ and there are two major stages to avoid defect as a folding defect.

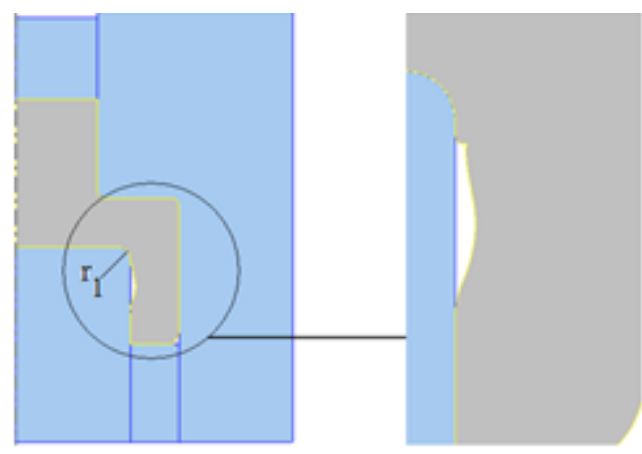

(a)

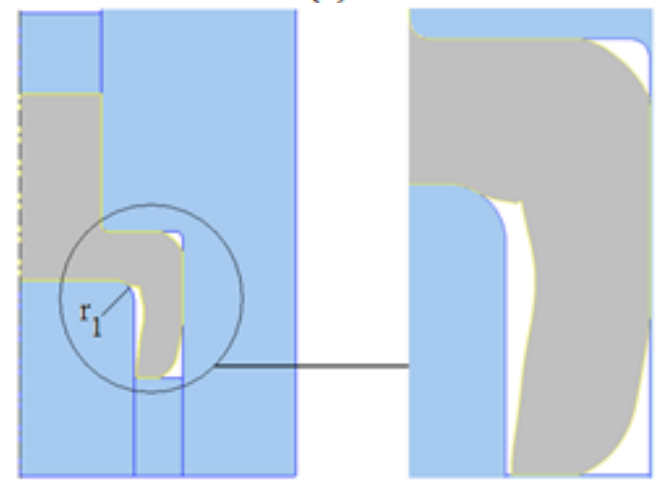

(b)

Figure 4: Folding defect in radial-forward extrusion process with different mandrel radius $\left(r_{1}\right): r_{1}=4 \mathrm{~mm}(\mathrm{a}), \mathrm{r}_{1}=6 \mathrm{~mm}$ (b)
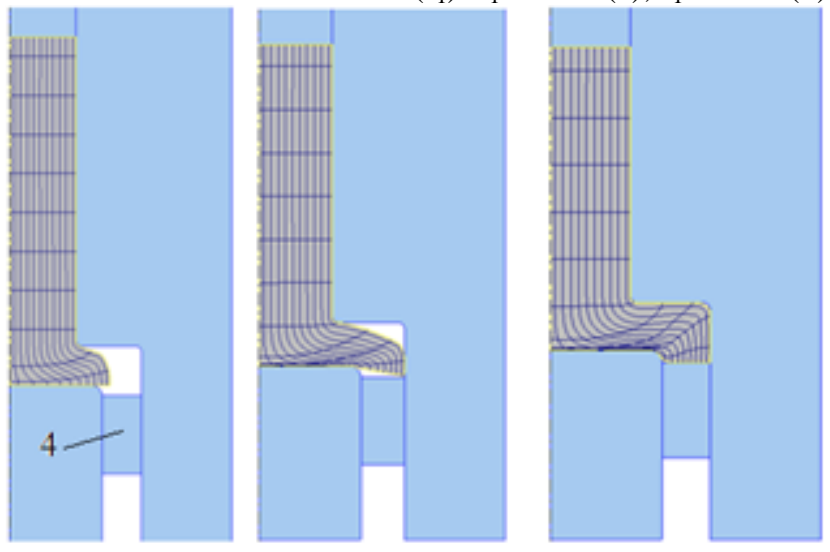

(a)
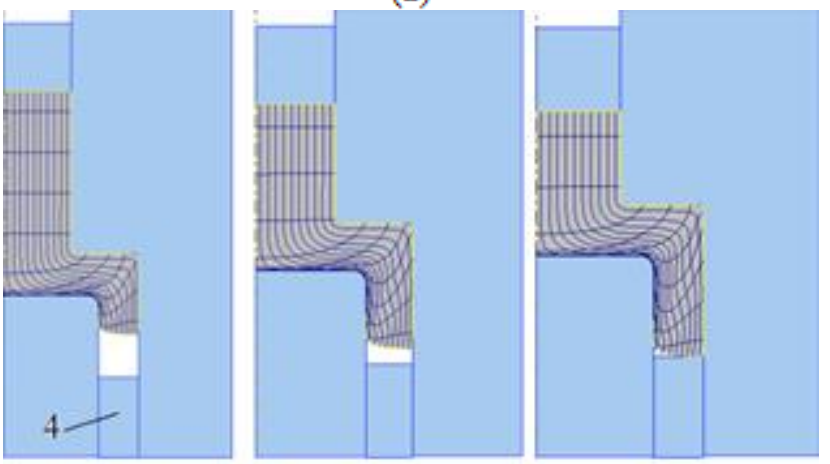

(b)

Figure 5: Material flow behaviors to avoid folding defect: first stage (a), second stage (b) and anvil (4)

\section{Acknowledgements}

The author acknowledge, Mr. Igramotdin Aliiev, Dr.Sc., Professor and Head of Metal Forming Department and also Mrs. Leila Aliieva, Ph.D., Associate Professor of Metal Forming Department at Donbass State Engineering Academy

\section{Volume 6 Issue 7, July 2017} www.ijsr.net 


\section{International Journal of Science and Research (IJSR) \\ ISSN (Online): 2319-7064 \\ Index Copernicus Value (2015): 78.96 | Impact Factor (2015): 6.391}

for their continuous support and encouragement for my research.

\section{References}

[1] Santos A. D., Duarte J. F., Reis A., da Rocha B., Neto R., Paiva, R., The use of finite clement simulation for optimization of metal forming and tool design. J. Mater. Process. Technol. 119, 152-157, 2001.

[2] Lee D. J., Kim D. J., Kim B. M., New processes to prevent a flow defect in the combined forwardbackward cold extrusion of a piston-pin. J. Mater. Process. Technol. 139, 422-427, 2003.

[3] Ishikawa T., Yukawa N., Yoshida Y., Tozawa Y., Analytical approach to elimination of surface microdefects in forging. CIRP Ann. Manuf. Technol. 54, 249-252, 2005

[4] Giuliano G., Process design of the cold extrusion of a billet using finite element method. Mater. Des. 28, 726729, 2007.

[5] Song J. H., Im Y. T., Process design for closed-die forging of bevel gear by finite element analyses. J. Mater. Process. Technol. 192, 1-7, 2007.

[6] Zhang G. L., Zhang S. H., Li B., Zhang H. Q., Analysis on folding defects of inner grooved copper tubes during ball spin forming. J. Mater. Process. Technol. 184, 393400, 2007.

[7] Fu M. W., Yong M. S., Tong K. K., Danno A., Design solution evaluation for metal forming product development. Int. J. Adv. Manuf. Technol. 38, 249257, 2008 .

[8] I. Aliiev, L. Aliieva, P. Abhari, K. Goncharuk, Investigation of defect in precision combined extrusion process with multiple ram / XVI International scientific conference New technologies and achievements in metallurgy, material engineering and production engineering. - Series : Monographs. - Czestochowa, Poland, 2015. - №48. - P. 90-93.

[9] Payman Abhari Investigation of load on the tools in precision radial extrusion process with multiple ram /Payman Abhari// XVII International scientific conference «New technologies and achievements in metallurgy, material engineering and production engineering» :Series: Monografie. - $\mathrm{Nr} 56$. Częstochowa, Poland, 2016 - P. 330-333.

[10] Payman Abhari Investigation of fracture moment in radial extrusion process by finite element method / Payman Abhari // XVIII International scientific conference New technologies and achievements in metallurgy, material engineering, production engineering and physics. - Series: Monografie. Częstochowa, Poland, 2017. - Nr 68. - C. 97-101.

\section{Author Profile}

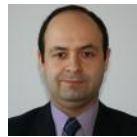

Dr. Payman Abhari, Ph.D., Associate Professor of Metal Forming Department at Donbass State Engineering Academy, Kramatorsk, Donetsk, Ukraine. $\mathrm{He}$ obtained his Ph.D. degree in Mechanical Engineering from Donbass State Engineering Academy, Ukraine in 2011. He has over 50 technical papers in the national and international journals and conferences. His fields of research are: Cold Forging, Extrusion Process and Finite Element Simulation 